\title{
Injection of Reagent Ions into the Selvedge Region in Fast-Atom Bombardment Mass Spectrometry
}

\author{
Jason C. Rouse and John Allison \\ Department of Chemistry, Michigan State University, East Lansing, Michigan, USA
}

A divided probe that incorporates a potassium aluminosilicate glass target and an analyte/glycerol matrix target, spatially separated, was used to inject potassium ions $\left(\mathrm{K}^{+}\right)$ into the high-pressure "selvedge" region formed above the analyte/glycerol matrix target during fast-atom bombardment (FAB); $[\mathrm{M}+\mathrm{K}]^{+}$adduct ions that represent the types of gas-phase neutral molecules present in the selvedge region are observed. Computer modeling assisted in designing the divided target and an additional ion optical clement for the FAB ion source to optimize interactions between $\mathrm{K}^{+}$ions and the desorbed neutral molecules. The capability of injecting $\mathrm{K}^{+}$ions into the $\mathrm{FAB}$ experiment has utility in both mechanistic studies and analyses. Experimental results here are consistent with a model for the desorption/ionization processes in $\mathrm{FAB}$ in which some types of neutral analyte molecules are desorbed intact and are subsequently protonated by glycerol chemical ionization. Unstable protonated molecules undergo unimolecular decomposition to yield observed fragment ions. The use of $\mathrm{K}^{+}$cationization of analytes for molecular weight confirmation is demonstrated, as well as its utility in FAB experiments in which mixtures are encountered. ( $J$ Am Soc Mass Spectrom 1993, 4, 259-269)

$\mathrm{F}$ Tast-atom bombardment (FAB) [1] is clearly a useful process for generating gas-phase ions from analytes that were not previously amenable to mass spectrometric analysis. The processes leading to the conversion of condensed-phase analy te to gas-phase ions are generally believed to depend on whether the analyte exists in neutral or ionic form in the matrix [2]. If, for example, a polar, nonionic analyte (M) is placed in the matrix, glycerol (G), with a molar $G / M$ ratio of 1000:1 or more, desorption and ionization are proposed to occur sequentially [3]. The fast-atom beam, impinging the sample on the surface of the target, generates gas-phase $G$ and $M$ molecules above the sample surface, in the so-called selvedge region. A small fraction of the molecules may be ionized by subsequent fastatom/desorbed molecule collisions or desorbed directly in ionic form. Because most of the liquid target is composed of $G$ molecules, most of these ions are related to $G$. Thus, essentially glycerol chemical ionization (CI) conditions are created. Initially formed ions related to glycerol undergo many collisions with $G$ molecules to generate the $[n \mathrm{G}+\mathrm{H}]^{+}$ion series, as well as leading to protonation of the analyte, forming $[\mathrm{M}+\mathrm{H}]^{+}$. Thus, a gas-phase selvedge model explains

Address reprint requests to John Allison, Department of Chemistry, Michigan State University, East Lansing, MI 48824. the formation of protonated analyte molecules, and it is consistent with the body of literature on proton affinities [4]. If the analyte is a salt, such as a tetraalkyl ammonium halide, $\mathbf{R}_{\mathbf{4}} \mathrm{N}^{+} \mathrm{X}^{-}$, which ionizes in glycerol, then fast atoms induce direct desorption of an ion such as $\left[R_{4} N\right]^{+}$. No further chemistry is needed to generate an ion representative of the analyte, although adduct formation may occur as this ion passes through the selvedge region, to form ions such as $\left[\mathrm{R}_{4} \mathrm{~N}+\mathrm{G}\right]^{+}$.

The analysis of a FAB spectrum is similar to the analysis of any $\mathrm{CI}$ spectrum, and similar questions must be addressed. Does the peak at highest mass-tocharge ratio value (that is not related to the matrix) represent the protonated analyte $[\mathrm{M}+\mathrm{H}]^{+}$or the radical cation $\mathrm{M}^{+}$, or are such forms of the analyte unstable? Does the peak at highest mass-to-charge ratio value represent a fragment of the protonated molecule such as the $\left[(\mathrm{M}+\mathrm{H})-\mathrm{H}_{2} \mathrm{O}\right]^{+}$species commonly seen for alcohols? Such questions become even more extensive because biological analytes may contain salts, and one may encounter adduct ions such as $[\mathrm{M}+\mathrm{Na}]^{+}$as well. Also, when salts are present in high concentrations, ions such as $[\mathrm{M}-\mathrm{H}+2 \mathrm{Na}]^{+}[5]$ may be observed. The choice of matrix in using $\mathrm{FAB}$ is a second complication that is obvious when one realizes that the differences in proton affinities of analyte molecules and matrix molecules may determine whether any ions 
representing the analyte will be formed. Third, there are many complications when mixtures are (intentionally or unintentionally) analyzed by FAB because it is a "batch" method. The ratio of ion currents representing the two components may be a poor representation of their relative concentrations in the liquid target. In some cases, this may be due to the preferential protonation of one component in the gas phase, owing to its relatively high proton affinity. In other cases, the preferential response for a compound may reflect the fact that it is surface active and thus is desorbed to a greater extent than other analytes in the matrix.

We demonstrate here that $\mathrm{K}^{+}$ions can be injected into the selvedge region of the $F A B$ experiment and that this capability will allow the neutral molecules formed by particle bombardment to be identified. Such a capability not only provides useful information on the mechanism of FAB, but it also provides useful analytical information. This work is an outgrowth of the technique of $\mathrm{K}^{+}$ionization of desorbed species ( $\left.\mathrm{K}^{+} \mathrm{IDS}\right)[6]$ that was developed in this laboratory. The $\mathrm{K}^{+}$IDS technique uses $\mathrm{K}^{+}$as the $\mathrm{CI}$ reagent ion for identifying molecules desorbed after the rapid heating of thermally labile analyte molecules. Potassium ions are very useful for such work because they do not induce fragmentation on interaction with organic molecules [7], cannot react by charge transfer owing to the very low ionization energy of potassium atoms, and only form adduct ions. Thus, they provide a straightforward probe of neutral molecules generated in an ion source. Because we use $\mathrm{K}^{+}$here to investigate neutral molecules desorbed by particle bombardment in the $\mathrm{FAB}$ experiment, we refer to the technique as $\mathrm{K}^{+}$IDS-by-FAB [8].

This work is not designed to prove that the selvedge region exists, nor are we attempting to define its dimensions. Desorbed neutral molecules and desorbed ions are present in the ion source during a FAB experiment, and we can use gas-phase chemistry to sample the desorbed neutral molecules. Whether this corresponds to sampling the selvedge region or not depends on individual views and definitions of the term [9-12].

To inject ions into the selvedge region of a normal FAB experiment, we investigated the use of a divided FAB target. One-half of the target would contain the typical glycerol/analyte mixture, and the other half would contain a material that, when subjected to FAB. would yield copious amounts of $\mathrm{K}^{+}$ions. Although Münster et al. [13], Miller et al. [14], and Michaud et al. [15] successfully demonstrated the use of divided targets to explore gas-phase ion formation mechanisms in FAB, the interactions of ions derived from one side of their targets with neutral molecules derived from the other side usually resulted in ion signals of much lower intensity than those that could be obtained when both analytes were mixed on a single target. We will provide some insight into this observation in the following sections.

\section{Experimental}

\section{Instrumental Parameters}

All mass spectra were obtained on a JEOL HX-110 double-focusing, forward geometry mass spectrometer equipped with the JEOL FAB gun, the JEOL JMADA5000 data system, and the combination JEOL field desorption/FAB (FD/FAB) ion source. For all experiments, the accelerating voltage was $10 \mathrm{keV}$; the resolution was 1000 ( $10 \%$ valley definition); and the scan rate was from $m / z 1-1500$ per minute. The fast atoms used were $6-\mathrm{keV}$ xenon atoms. A divided target was constructed by highly modifying a JEOL FAB target, as is described later. It was placed on the end of the JEOL direct-insertion probe.

\section{Computer Modeling of Ion Optics}

The dimensions of the target and ion source optical elements were modeled using the computer program SIMION PC/PS2 Version 4.0 [16]. "Electrodes" were scaled to fit the maximum potential array size of 16,000 points to ensure accuracy. The symmetry used was planar, nonsymmetrical. The set of electrode voltages used for each SIMION model was obtained by measuring the actual potentials of the ion optical elements in the JEOL FD/FAB ion source during a typical $\mathrm{K}^{+} \mathrm{IDS}-$ by-FAB experiment. The models were refined until the maximum voltage deviation in the array was $1 \times 10^{-4}$ $V$. Identical results were obtained with MacSIMION 2.0 [17], in which a more accurate, 330,000-point potential array was defined.

\section{Sample Preparation}

Stachyose, kassinin, cholic acid, digoxin, and bradykinin (Sigma Chemical, St. Louis, MO); polyethylene glycol 600 , benzyltriethylammonium chloride, and glycerol (Aldrich Chemical Co., Mikwaukee, WI); thevetin ( $\mathrm{K} \& \mathrm{~K}$ Laboratories, Cleveland, $\mathrm{OH}$ ); and $\mathrm{KNO}_{3}, \mathrm{Al}_{2} \mathrm{O}_{3}$, and $\mathrm{SiO}_{2}$ (Johnson Matthey $\mathrm{Co}$, Ward Hill, MA) were used without further purification. Analytes were dissolved either in methanol (J. T. Baker, Phillipsburg, NJ) or a 1:1 mixture of methanol and Milli-Q water (Millipore, Bedford, MA). The sample concentrations ranged from 2 to $10 \mu \mathrm{g} / \mu \mathrm{L}$. Spectroscopically pure glycerol was coated on either the $\mathrm{K}^{+}$IDS-by-FAB analyte/glycerol target half or the JEOL FAB target, and $1 \mu \mathrm{L}$ of sample solution was transferred to the respective target and mixed with the glycerol. The FAB spectrum of each compound was obtained with an alkali metal-free JEOL FAB target.

\section{Results and Discussion}

\section{$K^{+} I D S-b y-F A B$ Target Development}

The experimental design for injecting $\mathrm{K}^{+}$ions into the $\mathrm{FAB}$ experiment is conceptually very simple, but the 
most straightforward divided target designs that were investigated gave only limited success. Successful $\mathrm{K}^{+}$ ion injection in the $\mathrm{FAB}$ experiment for sampling desorbed neutral molecules is highly dependent on both the target geometry and the arrangement of, and potentials applied to, the ion source optical elements, because the region of highest pressure presumably occupies a small region of space above the sample target. With the aid of the ion optics computer modeling program, SIMION PC/PS2, a functional $\mathrm{K}^{+}$IDSby-FAB target was developed. Our experiences and insights are summarized here.

The design considerations of a divided target for $\mathrm{K}^{+}$IDS-by-FAB required that the FAB beam strike both a solid surface that would yield $\mathrm{K}^{+}$ions and the matrix/analyte target simultaneously, resulting in the injection of desorbed $\mathrm{K}^{+}$ions into the gaseous selvedge region above the matrix/analyte target. The $[\mathrm{M}+\mathrm{K}]^{+}$ adduct ions formed by this process would then be extracted and mass analyzed. A common way to generate gas-phase $\mathrm{K}^{+}$ions with $\mathrm{FAB}$ is to bombard a $\mathrm{KCl}$ film. Unfortunately, $\mathrm{FAB}$ of $\mathrm{KCl}$ yields $\mathrm{K}_{n} \mathrm{Cl}_{m}^{+}$cluster cations in addition to $\mathrm{K}^{+}$, and the $\mathrm{KCl}$ film on the target needs to be regenerated after each experiment. One key component of the $\mathrm{K}^{+}$IDS-by-FAB experiment is the generation of $\mathrm{K}^{+}$ions. In $\mathrm{K}^{+} \mathrm{IDS}$, a $\mathrm{K}^{+}$aluminosilicate glass emitter with the molar composition $\mathrm{K}_{2} \mathrm{O}: \mathrm{Al}_{2} \mathrm{O}_{3}: 2 \mathrm{SiO}_{2}$, generates copious amounts of gasphase $\mathrm{K}^{+}$ions; surprisingly few ncutral molecules arc emitted from such materials $(\leq 10 \%)$ when heated [18]. FAB of the same $\mathrm{K}^{+}$glass on a target surface at room temperature also yields continuous, copious amounts of gas-phase $\mathrm{K}^{+}$ions, with no evidence of charging [19]. The FAB mass spectrum of the $\mathrm{K}^{+}$glass (Figure 1) was obtained by exposing the $\mathrm{K}^{+}$IDS-by-FAB target, without a sample or glycerol present, to the fast-atom beam. The dominant peak represents the reagent ion $\mathrm{K}^{+}$. The small $\mathrm{Na}^{+}$ion signal at $m / z 23$ in Figure 1 arises from impurities in or on (or both) the $\mathrm{K}^{+}$glass emitter and target metal surfaces. The peak at $m / z 52$ represents $\mathrm{Cr}{ }^{\prime}$ sputtered from bare stainless steel surfaces. We believe that $\mathrm{K}^{+}$ion generation via the $\mathrm{K}^{+}$glass emitter is the optimal approach because copious amounts of $\mathrm{K}^{+}$ions are generated exclusively,

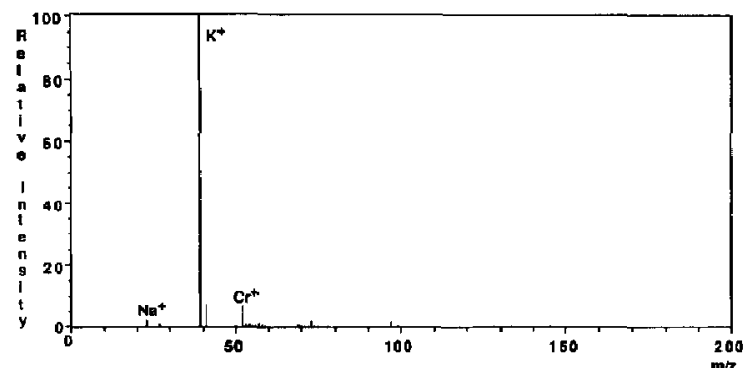

Figure 1. FAB mass spectrum of the $K^{+}$IDS-by-FAB target without matrix or analyte present. and a single $\mathrm{K}^{+}$glass target can be used for many experiments.

The first $\mathrm{K}^{+}$IDS-by-FAB work used a simple walldivided target [20] that is shown in Figure 2a. We concluded that this wall-divided target was unreliable, regardless of wall height $(0.1-1 \mathrm{~mm})$. Most often, this target resulted in little $[\mathrm{M}+\mathrm{K}]^{+}$adduct ion formation, and either the $\mathrm{K}^{+}$IDS-by-FAB spectra contained a peak representing the $\mathrm{K}^{+}$ion only or peaks representing the normal FAB matrix and analyte ions, depending on tuning parameters. In Figure 3 , a representative $\mathrm{K}^{+}$IDS-by-FAB mass spectrum for glycerol is shown in which adduct ion formation occurred. Such a spectrum is obtained when the $\mathrm{K}^{+}$glass emitter has been contaminated by condensed-phase material. An identical mass spectrum is obtained if glycerol is intentionally placed on the $\mathrm{K}^{+}$glass emitter and subjected to FAB. Apparently, the analyte/matrix can be sputtered onto the $\mathrm{K}^{+}$emitter by the fast-atom beam if the wall separating the two targets is too low. Also, the analyte/matrix can "creep" around and over the wall because the two target surfaces are physically connected. The abundant $[\mathrm{G}+\mathrm{K}]^{+}$adduct ion may be due in part to the desorption of the $[\mathrm{G}+\mathrm{K}]^{+}$ion directly from the surface of the $\mathrm{K}^{+}$glass emitter. The formation of the $[\mathrm{G}-\mathrm{H}+2 \mathrm{~K}]^{+}$adduct ion is the primary indicator that a condensed-phase interaction between $\mathrm{K}^{+}$glass and analyte/matrix has occurred. If the $[\mathrm{G}-\mathrm{H}+2 \mathrm{~K}]^{+}$ion appears in the mass spectrum, we cannot guarantee that the $[\mathrm{G}+\mathrm{K}]^{+}$adduct ion, as well as any $\mathrm{K}^{+}$adducts of analyte molecules observed, are formed in the gas phase.

To decrease the possibility of cross-contamination, as demonstrated by the wall-divided target, we designed the divided target shown in Figure $2 \mathrm{~b}$. With this "space-divided" target, the $\mathrm{K}^{+}$emitter and sample support are separated in space, but are close enough so that both targets can be bombarded simultaneously by fast atoms, and desorbed $\mathrm{K}^{+}$ions can interact with the desorbed neutral molecules above the sample target. The sample stage on a JEOL FAB target was bent to a $30^{\circ}$ angle, and rhenium wire $(0.007$ in.) connects the $\mathrm{K}^{+}$glass emitter to the target post. Unfortunately, this space-divided target has also performed inconsistently in converting a substantial fraction of $\mathrm{K}^{+}$ions into $[\mathrm{M}+\mathrm{K}]^{+}$and $[\mathrm{G}+\mathrm{K}]^{+}$adducts; however, it did

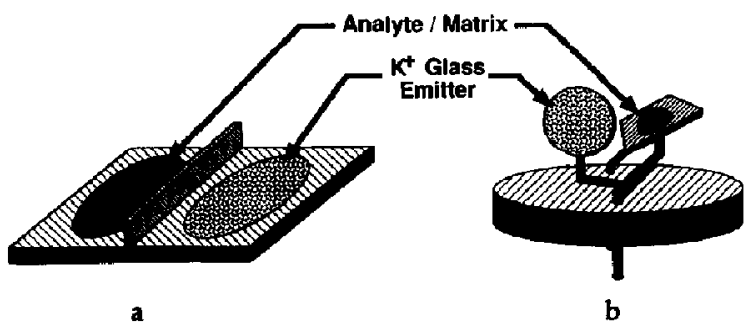

Figure 2. Schematics of (a) the $\mathrm{K}^{+}$IDS-by-FAB wall-divided target and (b) the $\mathrm{K}^{+}$IDS-by-FAB space-divided target. 


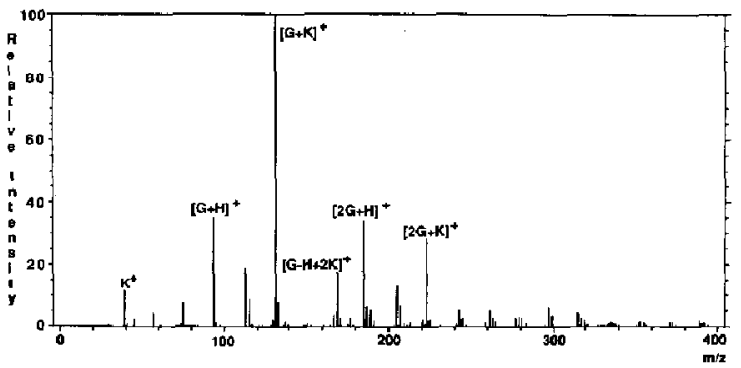

Figure 3. $K^{+}$IDS-by-FAB IIldss spectrum of glycerol when the $\mathrm{K}^{+}$glass emitter is contaminated with matrix/analyte.

solve the cross-contamination problem that plagued the wall-divided target because $[\mathrm{G}+\mathrm{K}]^{+}$adduct ions could be formed without $[\mathrm{G}-\mathrm{H}+2 \mathrm{~K}]^{+}$ion formation.

The ion optics computer modeling program SIMION was used to gain insight into the ion trajectories from $\mathrm{K}^{+}$IDS-by-FAB targets to improve performance. Representative computational results are presented below. The utility and limitations of the SIMION investigations should be clearly stated. "SIMION is a personal computer program for designing and analyzing charged particle lenses, ion transport systems, various types of mass spectrometers and surface probes that utilize charged particles" [21]. We are using it to gain insights into the influence of ion source modifications on the potential surface on which ions move within the ion source. The results presented here should not be interpreted literally, but are meant to assist in the design and analysis of the experiment. Obviously, the experimental goal is to generate ions from near a solid surface, and have them "sweep" through a region of space close to the matrix surface. The ionic trajectories are determined by the fields within the source. The best way to appreciate the topology of the electric fields is to follow some ion trajectories. This we do in the figures presented. In these trajectory studies, ions originate near a surface with an initial kinetic energy of zero. Clearly this is not an accurate description of the ions; however, ions with no initial kinetic energy are most sensitive to the potential surface on which they move. The other option would be to compute thousands of trajectories for a variety of possible initial kinetic energy vectors. Although such a rigorous approach may be informative, it must be realized that any trajectories computed cannot be accurate because SIMION will not allow ion-neutral molecule collisions to be considered. The point of the experiment is to inject ions into a high-pressure region of the ion source where collisions occur. Thus, we use SIMION to suggest physical possibilities. The SIMION results selected to be shown here are relevant in that they correlate well with what is observed. They correctly predict which variations of the $\mathrm{K}^{+}$IDS-by-FAB experiment should work; they predict qualitative tuning variations and sensitivity changes that are observed; and the combination of SIMION and experiments led to an experimental design that was effective. Thus, it should be realized that the SIMION results are shown to present insights into what could happen, the shape of the potential energy surface in the ion source, and how it can be distorted to achieve the desired result--the sampling of desorbed molecules by $\mathrm{K}^{+}$attachment.

SIMION was first used to consider the optimization of the spatial overlap between the $\mathrm{K}^{+}$ions from the glass emitter and the neutral molecules desorbed from the analyte/matrix target. In Figure 4a, a SIMION model of the normal FAB experiment that incorporates an ordinary JEOL FAB target placed in the JEOL $\mathrm{FD} / \mathrm{FAB}$ ion source is shown. The FD/FAB ion source electrodes and measured potentials are as follows: FAB target (repeller), 10,050 V; cathode (L1), 10,010 V; first focus (L2), $9000 \mathrm{~V}$; second focus (L3), $600 \mathrm{~V}$; deflector (L4), $30 \mathrm{~V}$; and total ion monitor plate (L5), $0 \mathrm{~V}$. The L3, L4, and L5 electrodes were included in the SIMION models, but are not shown in the figures. The FAB beam is also not shown, but it would originate from above the figure and strike the target with an average angle of incidence of $70^{\circ}$. The slits in L1 and L2 are 1 and $2 \mathrm{~mm}$ wide, respectively. Here, trajectories for eleven 100-Da cations, with initial energies of $0 \mathrm{eV}$, are shown starting at various locations near the FAB target. Of the 11 trajectories, only nine ions from the target area are successfully extracted by the penetrating electric ficlds (shown by the contour intervals labeled $\mathrm{C} 1-\mathrm{C} 4$ ). These ions pass through both $\mathrm{L} 1$ and L2, but the beam sharply diverges after L2. In Figure $4 b$, a SIMION model of the $K^{+}$IDS-by-FAB walldivided target is shown. Twenty-three total trajectories are shown; 11 ions originate on each half of the target,
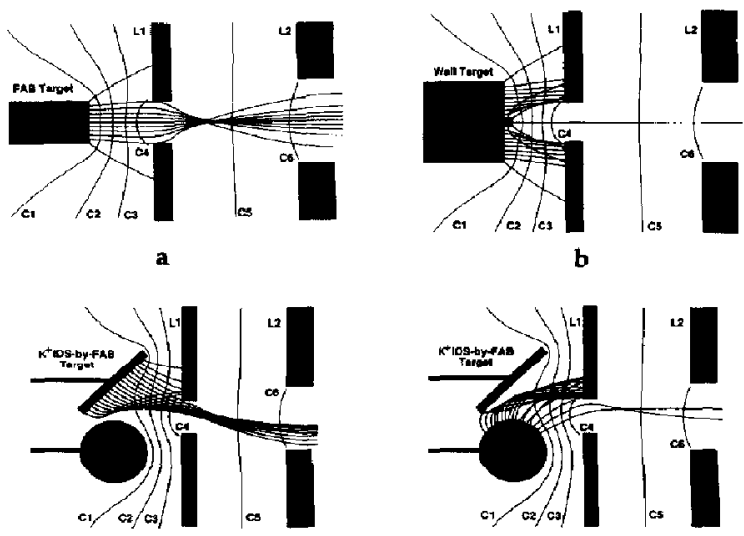

c

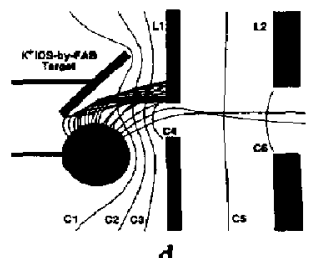

Figure 4. SIMION models of (a) the JEOL FD/FAB target and ion source; (b) the $\mathrm{K}^{+}$IDS-by-FAB wall-divided target; and the $\mathrm{K}^{+}$IDS-by-FAB space-divided target showing the fate of (c) analyte/matrix ions and (d) of $\mathrm{K}^{+}$ions. Contour lines representing the extraction field for the potentials $10,040 \mathrm{~V}(\mathrm{C} 1) ; 10,030 \mathrm{~V}(\mathrm{C} 2)$; $10,020 \mathrm{~V}(\mathrm{C} 3) ; 10,010 \mathrm{~V}(\mathrm{C} 4) ; 9500 \mathrm{~V}(\mathrm{C} 5) ;$ and $9000 \mathrm{~V}(\mathrm{C} 6)$ are shown. Source elements and potentials are described in the text for this $10-\mathrm{keV}$ ion source. 
and one originates on the wall. Unfortunately, only the ion that originates from the center of the target was successfully extracted. Our experimental results with the $\mathrm{K}^{+}$IDS-by-FAB wall-divided target coincide with the SIMION results shown here. The unreliable nature of the wall-divided target is illustrated by the SIMION model because the $\mathrm{K}^{+}$ions from the $\mathrm{K}^{+}$glass emitter surface diverge away from the selvedge region above the opposite target surface, preventing $[M+K]^{+}$ adduct formation. Because the contamination area of this target, discussed previously, is surely centered around the wall, the SIMION model suggests that ions from this central region would be easily extracted. It is also clear from the SIMION model in Figure $4 \mathrm{~b}$ why different tuning parameters were required to optimize extraction of analyte/glycerol ions, $\mathrm{K}^{+}$adduct ions from the wall area, and $\mathrm{K}^{+}$ions in the FD/FAB ion source. Three different sets of potentials were required for the optimum sampling of ions that originate from the three different regions on the target (left, center, and right). Thus, the SIMION models agree well with experimental observations.

Figure $4 \mathrm{c}$ and $\mathrm{d}$ show the SIMION model of the space-divided $\mathrm{K}^{+}$IDS-by-FAB target. Figure $4 \mathrm{c}$ shows the trajectories of 19 cations of mass $1000 \mathrm{Da}$ and with $0 \mathrm{cV}$ of initial kinctic encrgy originating from various locations near the stainless steel sample target. Twelve of the 19 ions are successfully extracted from the target area. These ions traverse both $\mathrm{L} 1$ and $\mathrm{L} 2$, but the beam is poorly defined, which is consistent with observed tuning problems. In Figure $4 \mathrm{~d}$, the trajectories are shown for $\mathrm{K}^{+}$ions originating from the $\mathrm{K}^{+}$glass. All but two trajectories terminate on the source element $\mathrm{L1}$; however, at least these $\mathrm{K}^{+}$ions do follow favorable trajectories, passing close to the presumed selvedge region. Experimental results with this space-divided $\mathrm{K}^{+}$IDS-by-FAB target are consistent with the $\mathrm{K}^{+}$ions trajectories, as shown in Figure $4 \mathrm{~d}$. The $[\mathrm{M}+\mathrm{K}]^{+}$ adduct ion formation occurred more often with this design than with the wall-divided target, but the $[\mathrm{M}+$ $\mathrm{K}]^{+}$adduct ion signal was still usually weak in comparison to any FAB matrix/analyte ions. A potential problem with this $\mathrm{K}^{+}$IDS-by-FAB target design is that a typical $\mathrm{K}^{+}$ion is promptly accelerated to kinetic energies of $2 \mathrm{eV}$ and greater in the presumed vicinity of the selvedge region, resulting in (1) short residence times and (2) kinetic energies too high for adduct formation [22]. As a result, many of the desorbed neutral molecules are not sampled by low-kinetic energy $\mathrm{K}^{+}$ions for the set of ion optical element voltages used in this SIMION calculation.

In an attempt to correct for the short residence time and high kinetic energy of the $\mathrm{K}^{+}$ions, an electrode, L0, with a center slit less than $1 \mathrm{~mm}$ wide and a potential equal to the target potential, was placed equidistant between the target electrode and the cathode electrode, L1, in the SIMION model to limit the extent of the extraction field penetration into the target area. The combination of the space-divided target and the electrode $L 0$ resulted in the ability to perform the $\mathrm{K}^{+}$IDS-by-FAB experiment as originally envisaged, and the reasons are shown in Figure $5 a-d$. The SIMIUN model in Figure 5a shows the normal FAB target, as shown in Figure $4 a$, in the $F D / F A B$ ion source that incorporates the additional electrode, L0, placed between the target and L1. Again, 11 ion trajectories from the FAB target surface are shown. The position and dimensions of the L0 electrode decrease the effects of the extraction voltages, as shown by the positions of the contour lines that correspond to the same potentials as those shown in Figure 4a. The presence of $\mathrm{LO}$ in the SIMION model still results in the extraction of 9 of the 11 ions, and it produces a well-defined ion beam compared with the ion beam shown in Figure 4a. Experimentally, the FAB spectrum is identical whether L0 is present or not. Figure $5 b$ shows the SIMION model of the wall-divided $\mathrm{K}^{+}$IDS-by-FAB target coupled with the additional electrode, Lo. The presence of $\mathrm{LO}$ in front of the wall-divided target dramatically increases the number of successfully extracted ions from 1 to 15 ( 7 ions from each target half) by decreasing the penetration of the extraction field. This design was never experimentally tested because SIMION results show that the $\mathrm{K}^{+}$ion overlap with the desorbed neutral molecules above the sample surface may still be insufficient, and previous experimental results showed that $\mathrm{K}^{+}$glass contamination readily occurs.

In Figure $5 c$ and $d$, the SIMION model of the space-divided $\mathrm{K}^{+}$IDS-by-FAB target coupled with the additional electrode, L0, is shown. In Figure 5c, 18 of 19 mlatrix/analyte FAB ions from the larget area are accelerated toward the analyzer in a well-defined beam, in contrast to the SIMION model shown in Figure 4c. In Figure $5 \mathrm{~d}$, all $\mathrm{K}^{+}$ions are injected into the presumed selvedge region above the sample target.

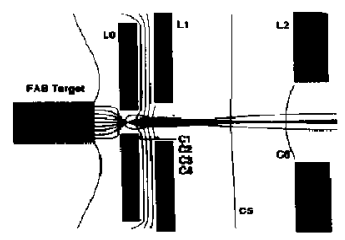

$\mathbf{a}$

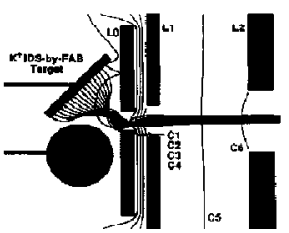

c

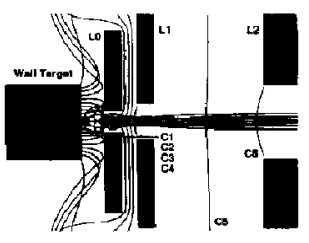

b

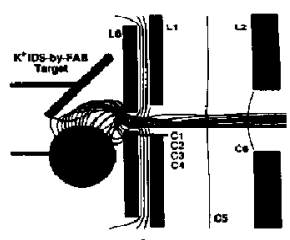

d
Figure 5. SIMION models with the additional ion optical element LO present: (a) the JEOL FD/FAB target; (b) the $\mathrm{K}^{+}$IDS-by$F A B$ wall-divided target; and the $K^{+} I D S-b y-F A B$ space-divided target, with trajectories shown for (c) analyte/matrix ions and (d) $\mathrm{K}^{+}$ions. Contour lines representing the potentials $10,040 \mathrm{~V}(\mathrm{C} 1)$; $10,030 \mathrm{~V}(\mathrm{C} 2) ; 10,020 \mathrm{~V}(\mathrm{C} 3) ; 10,010 \mathrm{~V}(\mathrm{C4}) ; 9500 \mathrm{~V}(\mathrm{C} 5) ;$ and 9000 $\mathrm{V}$ (C6) are also shown. 
SIMION trajectory calculations show that the L0 electrode increases the residence time and lowers the kinetic energy of the $\mathrm{K}^{+}$ions because the penetrating extraction fields stop sharply at LO, and essentially a field-free region is created between LO and the target. With the L0 ion optical element present, the typical $\mathrm{K}^{+}$ ions gain $2 \mathrm{eV}$ of kinetic energy, a realistic upper limit for $\mathrm{K}^{+}$adduct formation, in $4.5 \mu$ s and are present for approximately $1.9 \mu \mathrm{s}$ in the presumed area of the "selvedge region." Without LO installed (Figure $4 \mathrm{c}$ and d), typical $\mathrm{K}^{+}$trajectories achieve $2 \mathrm{eV}$ in $0.45 \mu \mathrm{s}$ and are present for approximately $0.3 \mu \mathrm{s}$ in the "selvedge region." Thus, there is substantially more opportunity for each $\mathrm{K}^{+}$ion to react with a desorbed neutral molecule with LO installed. In addition, a high-pressure region would probably be created in the small volume between the target and $\mathrm{L} 0$ electrode that would provide stabilization for termolecular ion-molecule adduct formation, if required. Experimentally, there were no visible traces of sample condensation on $\mathrm{LO}$. SIMION results clearly indicate that no preferential tuning problems should occur with the additional Lo ion optical element installed because all $\mathrm{K}^{+}$and matrix/analyte-related ions are focused into a welldefined beam. Experimental results below confirm this observation because $[\mathrm{M}+\mathrm{K}]^{+}$adducts and analyte/matrix ions appear in the same spectrum.

We incorporated the design shown in Figure $5 \mathrm{c}$ and $d$ into the $\mathrm{K}^{+}$IDS-by-FAB experiment with successful results. Figure $6 \mathrm{~b}$ shows the $\mathrm{K}^{+}$IDS-by-FAB spectrum of a glycerol sample obtained by using the space-di-
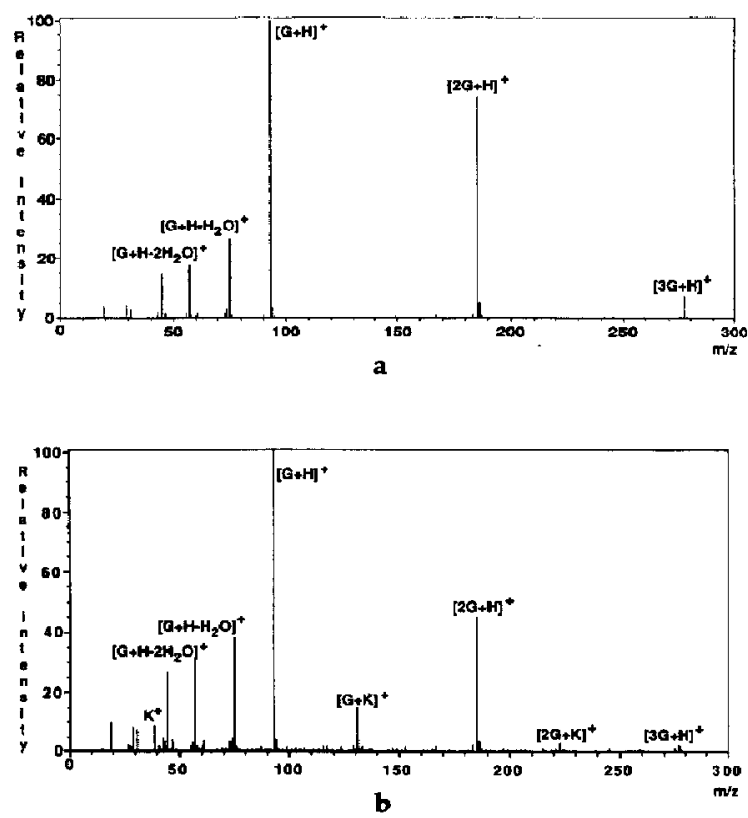

Figure 6. (a) FAB mass spectrum and (b) $\mathrm{K}^{+}$IDS-by-FAB mass spectrum of glycerol (MW 92). vided target with the ion optical element $L 0$ mounted in the $\mathrm{FD} / \mathrm{FAB}$ source, showing that $[\mathrm{G}+\mathrm{K}]^{+}$adduct ions can be formed without [G-H $+2 \mathrm{~K}]$ ' ions being formed. Thus, the analyte/liquid matrix is not being sputtered onto the $\mathrm{K}^{+}$glass. To confirm that these $[\mathrm{G}+\mathrm{K}]^{+}$ions are formed in the gas phase, one additional process needs to be considered. Although glycerol does not contaminate the $\mathrm{K}^{+}$glass, potassium could be sputtered into the matrix, yielding the observed adducts from condensed-phase, not gas-phase, processes.

The following observations and experiments suggest that potassium is not being sputtered from the thermionic emitter onto the liquid target in this experiment. First, we note that the $\mathrm{K}^{+}$IDS-by-FAB experiment is difficult to perform because it is very sensitive to the target design and positioning in relation to LO and the ion source. If significant amounts of potassium were sputtered from the glass to the liquid matrix and this led to $\mathrm{K}^{+}$adducts, the results should be much less sensitive to experimental design. For example, the designs shown in Figure $4 b-d$ should yield $[G+K]^{+}$ and $[\mathrm{M}+\mathrm{K}]^{+}$ions as well as those shown in Figure $5 \mathrm{~b}-\mathrm{d}$; this was not the case. Second, the emission properties of alkali aluminosilicate glasses suggest that the particle-induced desorption of $\mathrm{K}(\mathrm{g})$ need not occur to a greater extent than for $\mathrm{K}^{+}(\mathrm{g})$ owing to the nature of these materials and their performance as thermionic cmitters. Third, if potassium is sputtered into the liquid matrix in this experiment, and this is the process by which $\mathrm{K}^{+}$adducts are formed, then a time dependence should be observed. There should be no $\mathrm{K}^{+}$ adducts formed when the FAB experiment begins, and the adduct ion signals should increase with time as sputtered potassium accumulates in the matrix. This is not observed. The $\mathrm{K}^{+}$adduct signals are present when $F A B$ is first initiated, and the adduct ion signals are constant for a period of several minutes. Fourth, experiments have been performed to test transfer of potassium from the emitter to the sample target. For example, if no glycerol is added, and the space-divided target is bombarded for several minutes, potassium may be sputtered onto the bare sample surface on which glycerol is usually deposited. If the $\mathrm{K}^{+}$emitter is then removed and the bare surface subjected to $F A B$ analysis, there is no evidence for the accumulation of potassium on this surface. This is also true when glycerol is placed on the second target. If the space-divided target is bombarded for a period of time, the $\mathrm{K}^{+}$ emitter removed, and the remaining glycerol analyzed by $F A B$, there is no evidence for detectable concentrations of potassium in the glycerol. In some cases, a very small peak that could represent $\left[\mathrm{G}+\mathrm{K}^{+}\right.$could be observed, but it was barely detectable and very much smaller than those observed in the $\mathrm{K}^{+}$IDS-by$\mathrm{FAB}$ experiment. Also, experiments that involved the addition of various concentrations of $\mathrm{KCl}$ to glycerol demonstrated that if potassium was sputtered into the glycerol and this process leads to $\mathrm{K}^{+}$adducts, then 
other ions should be present in these spectra, such as $[\mathrm{G}-\mathrm{H}+2 \mathrm{~K}]^{+}$; these are not observed.

\section{Probing the Selvedge Region of the FAB Experiment with $K^{+}$Ions}

Injection of $\mathrm{K}^{+}$ions into the selvedge region of the FAB experiment will allow the desorbed neutral molecules to be identified. That is, if $\mathrm{K}^{+}$ions are injected into the FAB experiment and some $[\mathrm{M}+\mathrm{K}]^{+}$ ion is formed, we will interpret this as evidence for the presence of desorbed $M$ molecules in the selvedge region. We use this capability here to investigate the fate of analyte molecules for a variety of analyte compounds. Do they desorb as intact neutral molecules, or does FAB lead to desorbed molecular fragments as well?

Glycerol. The ions formed by FAB of glycerol are shown in Figure 6a. It is well known that a sequence of peaks representing protonated glycerol clusters, [ $n \mathrm{G}$ $+\mathrm{H}]^{+}$, dominates the spectrum and begins with $n=1$ at $m / z$ 93. In addition, two prominent "fragment ions" are represented by peaks at $m / z 75$ and 57 , which are 18 and $36 \mathrm{Da}$ below $m / z 93$, respectively.

Consider the ion at $m / z 75$. There are a variety of mechanisms by which this ion could be formed. The ion may be formed as a fragment ion of $\mathrm{G}^{+}$, or it may be a fragment formed from $[\mathrm{G}+\mathrm{H}]^{+}$. Because it is an even-electron ion, it may well be a fragment formed following protonation and should be written as [ $(\mathrm{G}+$ $\mathrm{H})-\mathrm{H}_{2} \mathrm{O}{ }^{+}$. Another possibility is that $\mathrm{FAB}$ imparts sufficient energy to the sample to induce dehydration. Thus, FAB could lead to the desorption of G, [G $\mathrm{H}_{2} \mathrm{O}$ ], and [ $\mathrm{G}-2\left(\mathrm{H}_{2} \mathrm{O}\right)$ ] into a gaseous, protonating environment, leading to the ionic species $\left[\mathrm{G}+\mathrm{H}^{+}\right.$, $\left[\left(\mathrm{G}-\mathrm{H}_{2} \mathrm{O}\right)+\mathrm{H}\right]^{+}$, and $\left[\left(\mathrm{G}-2\left(\mathrm{H}_{2} \mathrm{O}\right)\right)+\mathrm{H}\right]^{+}$at $m / z$ 93,75 , and 57 , respectively.

When $\mathrm{K}^{+}$ions are injected into the selvedge region above the glycerol target during FAB, an ion series corresponding to $[n \mathrm{G}+\mathrm{K}]^{+}$is observed that parallels the $[n \mathrm{G}+\mathrm{H}]^{+}$series (Figure $6 \mathrm{~b}$ ). This indicates that $\mathrm{K}^{+}$ions are successfully being injected into a highpressure region and are undergoing multiple collisions. This process is also indicated by the ratios of the peaks representing $\mathrm{K}^{+}$and its glycerol adducts; there is fairly extensive conversion of this "CI reagent ion" into product ions, which can occur in a high-pressure environment. The relative intensities of both the $[n \mathrm{G}$ $+\mathrm{K}^{+}$series and the $[n \mathrm{G}+\mathrm{H}]^{+}$series correlate with each other and are a function of the amount of glycerol present. The members of both series with small values of $n$ always dominate, and the low relative intensities of the higher mass ions in each series suggest that they are formed by sequential clustering processes in a high-pressure environment $[10,23]$. That is, it appears that $\mathrm{FAB}$ induces the desorption of single glycerol molecules and not glycerol clusters. More important, the $[n \mathrm{G}+\mathrm{K}]^{+}$ions are the only new ions formed when $\mathrm{K}^{+}$ions are injected. There are no peaks observed corresponding to $\left[\left(\mathrm{G}-n \mathrm{H}_{2} \mathrm{O}\right)+\mathrm{K}\right]^{+}$ions, suggesting that the fast-atom beam desorbs glycerol molecules, predominantly intact, and does not lead to desorbed degradation products. This is somewhat unexpected because elimination of water from alcohols is a very low-energy process, compared with the other processes that occur, such as desorption (vaporization). If $\left[\mathrm{G}-\left(\mathrm{H}_{2} \mathrm{O}\right)\right]$ molecules were desorbed, we would expect $\mathrm{K}^{+}$adducts to be formed. Although the $\mathrm{K}^{+}$ affinities for $\left[\mathrm{G}-\left(\mathrm{H}_{2} \mathrm{O}\right)\right]$, a diol, and $\left[\mathrm{G}-2\left(\mathrm{H}_{2} \mathrm{O}\right)\right]$, an alcohol, would be lower than that for glycerol, a triol, $\mathrm{K}^{+}$has been observed to readily form adducts with small molecules such as alcohols. Thus, we suggest that the ions observed at $\mathrm{m} / z 75$ and 57 should be considered fragment ions of $[\mathrm{G}+\mathrm{H}]^{+}$; the elimination of water occurs following protonation.

Cholic acid. Cholic acid [molecular weight (MW) 408], a bile acid, can be considered an example in which positive-ion FAB mass spectrometry "fails." The FAB mass spectrum of cholic acid in glycerol is shown in Figure 7a. There is a very small $\left[\mathrm{M}+\mathrm{H}^{+}\right.$signal at $m / z$ 409. The dominant ions are at $m / z 355$ and 373. These fragment ions are even-electron ions and correspond to a protonated molecule in which multiple water molecules have been lost. Again, there are two extreme situations that could explain the observed
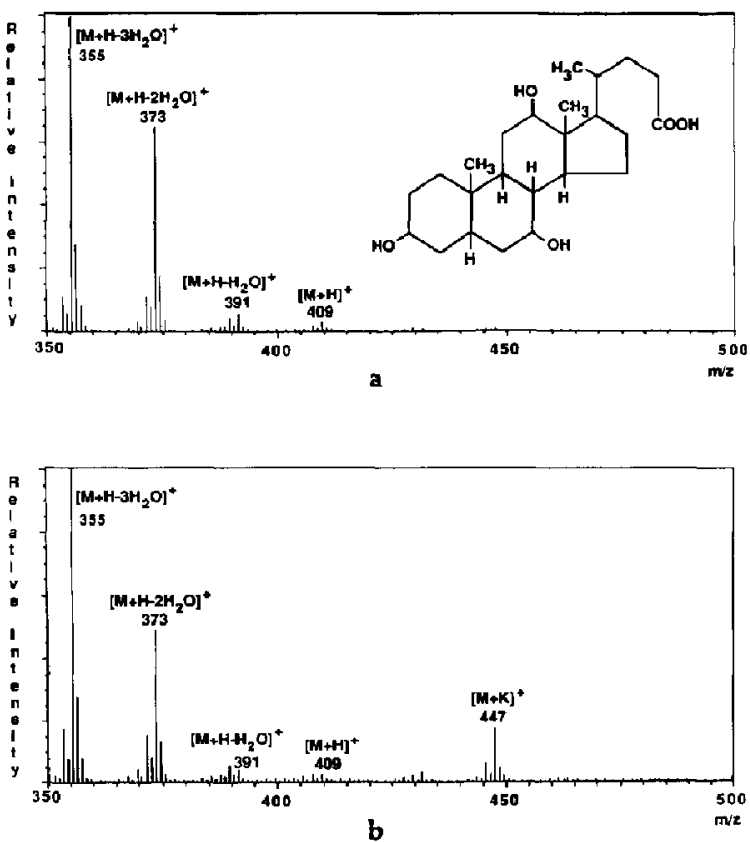

Figure 7. (a) FAB mass spectrum and (b) $\mathrm{K}^{+} \mathrm{IDS}-\mathrm{by}-\mathrm{FAB}$ mass spectrum of cholic acid (MW 408) in glycerol. 
spectrum. First, cholic acid molecules could be desorbed intact by FAB and subsequently protonated in the gas phase. Because the protonated molecule is unstable, the $[\mathrm{M}+\mathrm{H}]^{+}$ions essentially completely dissociate by losing one, two, and three water molecules. This would not be unexpected for a molecule containing multiple $-\mathrm{OH}$ groups under $\mathrm{CI}$ conditions. Also, not unexpected, would be a situation in which the polar molecule simply is not desorbed intact on FAB, but instead the dominant analyte-related molecules that desorb are the less polar, dehydrated forms $\left[\mathrm{M}-3 \mathrm{H}_{2} \mathrm{O}\right]\left(\mathrm{MW} \mathrm{354)}\right.$ and $\left[\mathrm{M}-2 \mathrm{H}_{2} \mathrm{O}\right]$ (MW 372), which then become protonated to yield the ion currents at $m / z 355$ and 373 . Figure $7 b$ shows the corresponding $\mathrm{K}^{+}$IDS-by-FAB mass spectrum for cholic acid. When $\mathrm{K}^{+}$ions are injected into the selvedge region, only one additional peak (not including those related to glycerol) appears, at $m / z$ 447, which is the $\mathrm{K}^{+}$adduct of the intact cholic acid molecule. There is no peak observed at $m / z 393$, which would represent $\left[\left(\mathrm{M}-3\left(\mathrm{H}_{2} \mathrm{O}\right)+\mathrm{K}\right]^{+}\right.$. Thus, the $\mathrm{K}^{+}$IDS-by-FAB results suggest that $F A B$ desorbs intact cholic acid molecules that dissociate completely on protonation. Although the protonated molecule is unstable, the neutral analyte molecules remain intact throughout the desorption process. The results shown in Figure $7 b$ also demonstrate that $\mathrm{K}^{+}$adducts of molecules are stable [24]; $\mathrm{K}^{+}$ forms adducts without inducing fragmentation and is thus ideal for such experiments. When a cholic acid/ $\mathrm{KCl}$ (low concentration)/glycerol mixture is subjected to $F A B$, an $[M-H+2 K]^{+}$ion is formed, but in $\mathrm{K}^{+}$IDS-by-FAB of cholic acid, this ion is not formed (see Figure $7 b$ ).

Digoxin. As the size of the analyte molecules increases, the possibility for fragmentation accompanying neutral desorption increases as well. The FAB spectrum of the cardiac glycoside, digoxin (MW 780), is shown in Figure 8a. An intense peak at $m / z 781$ representing the protonated molecule is observed, as is a rich array of fragment ions. Do all fragment ions result from the unimolecular fragmentation of the protonated molecule, or does the molecule decompose on fast-atom impact to yield an array of smaller $_{r}$ evenmass neutral molecules, each of which become protonated following dissociation? For example, the peak at $m / z 651$ represents the protonated form of digoxin $\left(\left[\left(\mathrm{AOS}_{1} \mathrm{OS}_{2} \mathrm{OS}_{3} \mathrm{OH}\right)+\mathrm{H}\right]^{+}\right)$minus the terminal sugar, $\mathrm{S}_{3}$, due to cleavage of a glycosidic bond, written as $\left[\left(\mathrm{AOS}_{1} \mathrm{OS}_{2} \mathrm{OH}\right)+\mathrm{H}\right]^{+}$using the Light-Kassel-Allison notation [25]. The aglycone is represented by $A$, and the sugars are designated as $\mathrm{S}_{n}$. Does $\mathrm{FAB}$ of the digoxin/glycerol target lead to desorption of [AOS $\mathrm{OS}_{2} \mathrm{OH}$ ] molecules (MW 650) that become protonated following desorption? Figure $8 b$ shows the $\mathrm{K}^{+}$IDS-by-FAB mass spectrum for this analyte. Again, on injection of $\mathrm{K}^{+}$ions into the $\mathrm{FAB}$ experiment, only one new analyte-related peak is formed, seen at $m / z$ 819 , representing the $\mathrm{K}^{+}$adduct of the intact digoxin
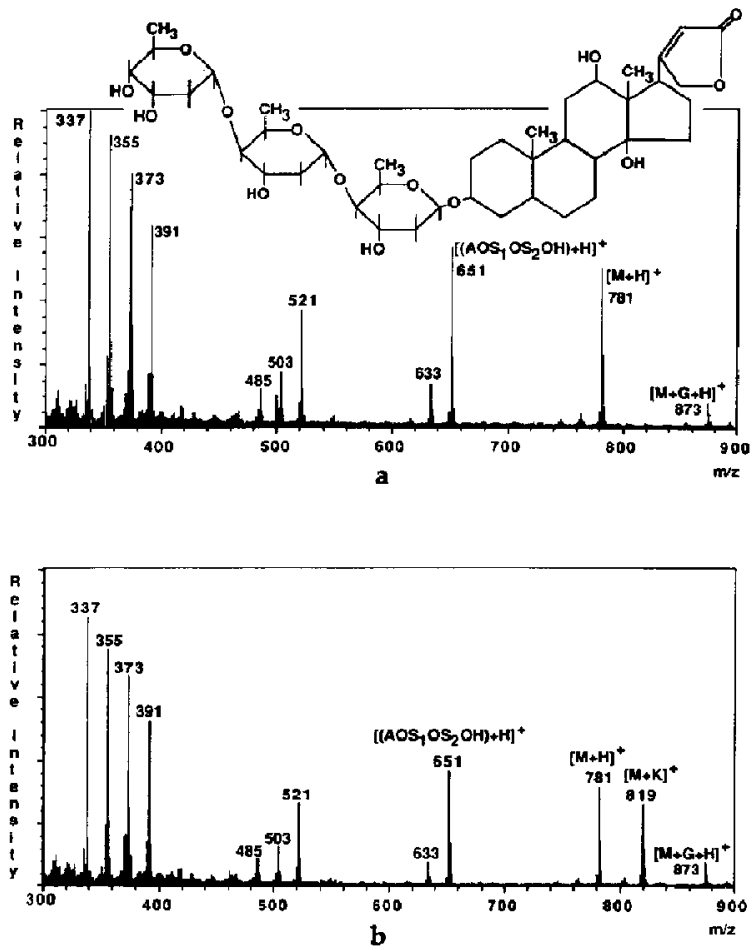

Figure 8. (a) FAB mass spectrum and (b) $K^{+}$IDS-by-FAB mass spectrum of digoxin (MW 780) in glycerol.

molecule. Thus, we conclude that FAB results in the intact desorption of polar digoxin molecules from the glycerol matrix; the analyte is protonated following desorption. The lower mass ions can be interpreted as true fragment ions of the protonated molecule.

Benzyltriethylammonium chloride. When this salt (MW 227) is analyzed by FAB, using glycerol as a matrix, the resulting spectrum is dominated by the benzyltriethylammonium cation $\left[\mathrm{C}_{13} \mathrm{H}_{22} \mathrm{~N}\right]^{+}$at $m / z$ 192. Fragments of this cation are also observed. We assume that this "preformed" cation desorbs directly as an ion, although one could certainly foresee, through a rearrangement reaction, the formation and subsequent desorption of a neutral species, $\left[\mathrm{C}_{13} \mathrm{H}_{21} \mathrm{~N}\right]$, which would then be protonated to yield a peak at $m / z$ 192. Another possibility is the intact salt desorbs and becomes protonated, as suggested by eq 1 :

$$
\begin{gathered}
{\left[\mathrm{C}_{13} \mathrm{H}_{22} \mathrm{~N}\right]^{+} \mathrm{Cl}^{-}(g)+[\mathrm{G}+\mathrm{H}]^{+} \stackrel{-\mathrm{G}}{\longrightarrow}} \\
\left.\left[\left[\mathrm{CC}_{13} \mathrm{H}_{22} \mathrm{~N}\right]^{+} \mathrm{Cl}^{-}\right)+\mathrm{H}\right]^{+} \longrightarrow \\
{\left[\mathrm{C}_{13} \mathrm{H}_{22} \mathrm{~N}\right]^{+}+\mathrm{HCl}}
\end{gathered}
$$

When $\mathrm{K}^{+}$IDS-by-FAB is used to probe the selvedge region in this experiment, no new ions representing the analyte are formed. Thus, direct desorption of preformed ions does appear to be the correct mechanism for such molecules. 
Peptides. The behavior of peptides in the $\mathrm{K}^{+}$IDS-byFAB experiment varies, which suggests that the mechanisms for ion formation should depend on the specific peptide under study. When the peptide kassinin (MW 1334) is analyzed by FAB using glycerol as the matrix, an abundant protonated molecule is formed. A portion of the $\mathrm{K}^{+}$IDS-by-FAB spectrum of kassinin is shown in Figure 9. The appearance of the additional peak at $m / z 1373,38$ Da above the protonated molecule, represents the potassium adduct of the intact, desorbed peptide. Even for an analyte of this size, FAB appears to induce the desorption of the analyte intact.

Bradykinin (MW 1059) also forms an abundant protonated molecule at $m / z$ 1060; however, when the $\mathrm{K}^{+}$IDS-by-FAB experiment is performed, and $\mathrm{K}^{+}$ions are injected into the selvedge region, no new ions are formed representing the analyte. Apparently, bradykinin exists in glycerol in protonated form and desorbs directly as an ion. This may be due to the very basic arginine residues in the peptide. Thus, even in a simple glycerol matrix, without addition of acid or base, peptides may behave in a variety of ways, depending on the $\mathrm{p} K_{\mathrm{a}} \mathrm{s}$ of the various basic sites in the molecule.

\section{Analytical Applications of $K{ }^{+}$IDS-by-FAB}

The obvious analytical utility of $K^{+}$IDS-by-FAB, in the context of FAB analyses, is the molecular weight confirmation for analytes that are not preionized in the matrix. Such capabilities are demonstrated in the cholic acid example in Figure $7 a$ and $b$. If this were an unknown, the 18-Da difference between $m / z 355$ and 373 would certainly be recognized as a water loss; however, one would probably not be able to distinguish the peaks at $m / z 391$ and 409 above the background. Thus, one may assume that the molecular weight of the analyte was 372 . In addition to those cases in which analytes yield very small peaks in the molecular weight region of the spectrum, $\mathrm{K}^{+}$IDS-by$\mathrm{FAB}$ is also useful in this regard when the mass-tocharge ratio of the protonated molecule coincides with that of a matrix-related ion. Similar cationization studies can be done by adding $\mathrm{KCl}$ or $\mathrm{KI}$ to the matrix,

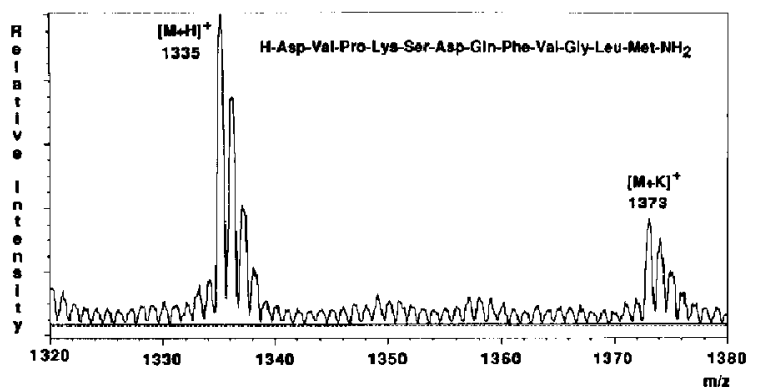

Figure 9. $K^{+}$IDS-by-FAB mass spectrum of kassinin (MW 1334) in glycerol. although this can lead to other ions in addition to an $[\mathrm{M}+\mathrm{K}]^{+}$ion.

A common occurrence that can "mask" molecular weight information in FAB is the formation of analyte/matrix cluster ions. For example, Figure $8 \mathrm{a}$ and $\mathrm{b}$ shows a peak at $m / z$ 873, which is the proton-bound adduct ion of digoxin and glycerol. Usually, the 92-Da difference between the peaks at $m / z \quad 781$ and 873 would be recognized as an adduct ion containing a single-matrix molecule, although the peak at $m / z 873$ could represent either the protonated analyte or a second component with a molecular weight 92 greater than that of digoxin. Again, the $K^{+}$IDS-by-FAB results clearly indicate the molecular weight of the compound and assist in identifying the high-mass ions that are candidates for pseudomolecular ions.

Another typical situation arose in obtaining the FAB mass spectrum of stachyose (MW 666), an oligosaccharide. The peak representing the protonated molecule is discernible but of low intensity, comparable to the intensities of nearby matrix-related ions in the mass spectrum. Actually, in some experiments with this analyte, no protonated parent was observed at all. Its formation was dependent on the glycerol/stachyose ratio used. Also, sodium salt impurities in the sample led to an $[\mathrm{M}+\mathrm{Na}]^{+}$peak $22 \mathrm{Da}$ above the protonated molecule. Figure 10 shows the $\mathrm{K}^{+}$IDS-by-FAB mass spectrum of stachyose, which clearly allows the molecular weight to be verified and the assignments for the peaks at $m / z 667$ and 689 to be confirmed.

$\mathrm{K}^{+}$IDS-by-FAB also provides useful information when mixtures are the subject of a FAB analysis. The use of FAB mass spectrometry for the analysis of mixtures always presents particular challenges, especially if no chromatographic information is available for the sample. A mixture that has received much attention in the desorption/ionization literature is that encountered in polyethylene and polyproplyene glycols. For example, polyethylene glycol (PEG) 600 is a mixture of oligomers with the formula $\left[\mathrm{H}\left(\mathrm{OCH}_{2} \mathrm{CH}_{2}\right)_{n} \mathrm{OH}\right]$. The distribution of oligomers is such that the average molecular weight is approximately 600 . One can obtain information on the oligomer distribution by FAB. If a small amount of PEG is added to a glycerol matrix, a series of protonated

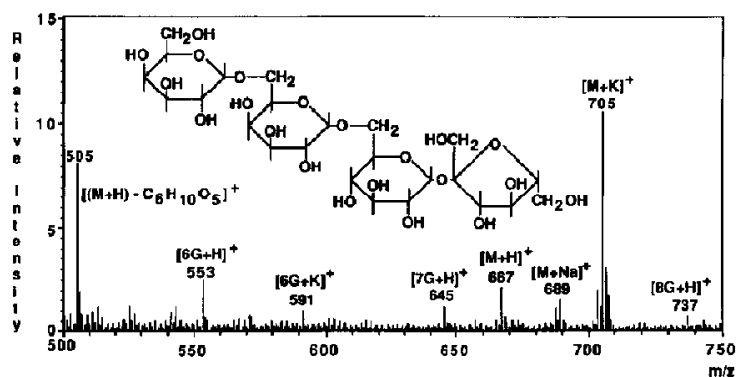

Figure 10. $\mathrm{K}^{+}$IDS-by-FAB mass spectrum of stachyose (MW 666) in glycerol. 
oligomers appears in the resulting $F A B$ mass spectrum. Figure 11 shows the $\mathrm{K}^{+}$IDS-by-FAB spectrum of PEG 600 . The $\mathrm{K}^{+}$adducts of each oligomer clearly stand out and dominate over all other ions formed. Again, as in the single-component analyses, FAB appears to induce the desorption of all of the oligomers present in the mixture intact.

In our work to understand the fragmentation of cardiac glycosides [26], we obtained the FAB mass spectrum of thevetin (MW 858) that is shown in Figure 12a. As expected, a peak representing the protonated molecule was present at $m / z$ 859; unexpected was a second peak $14 \mathrm{Da}$ higher at $m / z 873$. It is rare to find high-mass ions separated by $14 \mathrm{Da}$ because the loss of $\mathrm{CH}_{2}$ is rarely observed in unimolecular dissociations. A more reasonable explanation was that a mixture of two compounds was present with MWs 858 and 872 in approximately a 3:1 ratio, respectively. An investigation revealed that there are two forms of thevetin, thevetin $A$ and $B$, whose structures, as indicated on Figure 12a, differ by $14 \mathrm{Da}$. Apparently these two compounds are difficult to separate. The $\mathrm{K}^{+}$IDS-byFAB mass spectrum of thevetin (Figure 12b) confirms the presence of two compounds that differ in mass by $14 \mathrm{Da}$ because two additional ions are formed on injection of $\mathrm{K}^{+}$ions. If one looks more closely at the spectrum in Figure 12a, the relative abundances of the isotopic clusters for protonated thevetin A and B are very different, particularly at $m / z$ 875. In fact, this same isotopic distribution also appears in the $\mathrm{K}^{+}$IDSby-FAB spectrum in Figure $12 \mathrm{~b}$, suggesting that the sample is at least a three-component mixture. The third compound may be a reduced variant of thevetin A.

Last, it should be noted that the $\mathrm{K}^{+}$adduct of the intact analyte can be selected for collision-activated dissociation (CAD) or metastable analysis in the $\mathrm{K}^{+}$IDS-by-FAB experiment. The product ions of the $\mathrm{K}^{+}$IDS-by-FAB precursor $[\mathrm{M}+\mathrm{K}]^{+}$adduct ions, formed in the gas phase, are the same as those observed for the $[\mathrm{M}+\mathrm{K}]^{+}$ions formed when $\mathrm{KI}$ is added to the peptide/glycerol matrix. The utility of CAD for alkali cationized molecules in providing structural information has been demonstrated [27] and appears to be a method that can provide complementary informa-

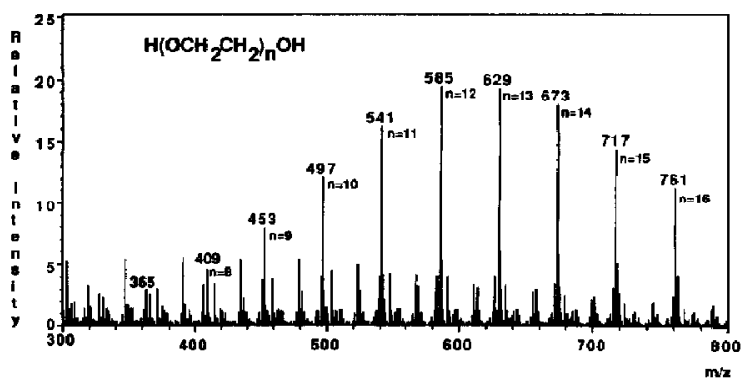

Figure 11. $\mathrm{K}^{+}$IDS-by-FAB mass spectrum of polyethylene glycol 600 in glycerol.
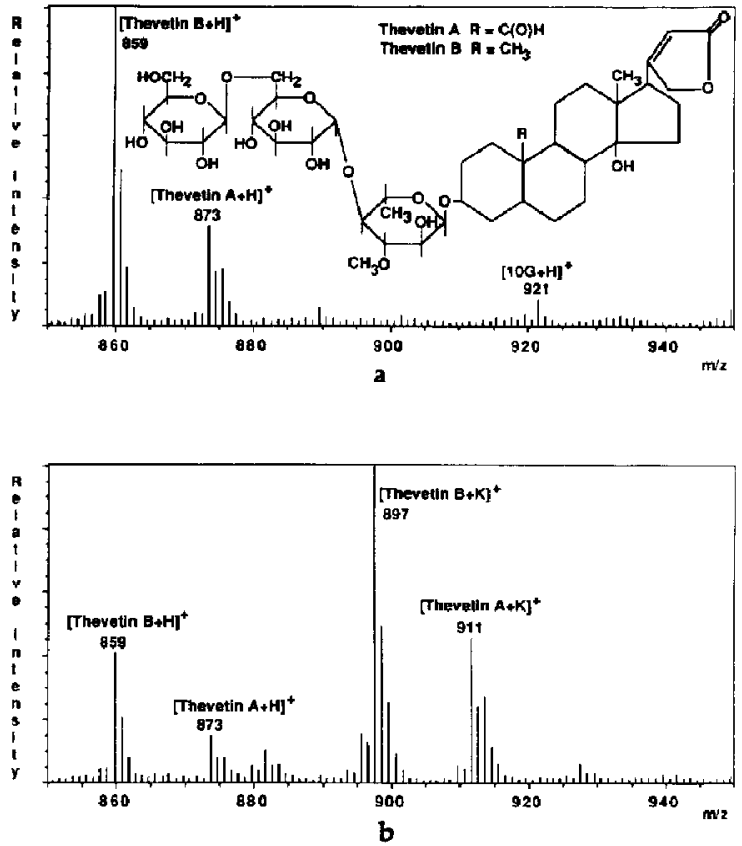

Figure 12. (a) FAB mass spectrum and (b) $\mathrm{K}^{+}$IDS-by-FAB mass spectrum of thevetin A (MW 872) and thevetin B (MW 858) in glycerol.

tion to that available from CAD studies of protonated molecules.

\section{Conclusions}

We have demonstrated that $\mathrm{K}^{+}$ions can be successfully injected into the selvedge region of the FAB experiment to probe the desorbed neutral species present. The K' IDS-by-FAB technique is both a mechanistic and an analytical tool. Mechanistically, the desorption aspects of $\mathrm{FAB}$, for both analyte and matrix molecules, can be probed. Analytically, $\mathrm{K}^{+}$cationization of analytes is useful for molecular weight confirmation.

One assumption central to the $\mathrm{K}^{+}$IDS-by-FAB data discussed here is that $\mathrm{K}^{+}$will form adduct ions with a variety of neutral molecules in the FAB ion source and that there are no dramatic differences in adduct formation rates for the molecules under consideration. Certainly, the details of this assumption remain to be explored. For example, in the experiments with glycerol, $\mathrm{K}^{+}$forms a complex with glycerol but not with dehydrated glycerol, and this is interpreted as suggesting that desorbed, dehydrated glycerol is not a major product of particle bombardment. This assumes that $\mathrm{K}^{+}$will form an adduct with $\left[\mathrm{G}-\mathrm{H}_{2} \mathrm{O}\right.$. At this point, we make two observations. First, $\mathrm{K}^{+}$and other alkali ions form adducts with monofunctional molecules such as alcohols and small molecules such as propene, so that multiple functional groups are not required [7, 
28]. Second, polar groups need not be present in a molecule for a substantial binding energy to an alkali ion. Because the interaction is electrostatic, both the dipole moment and the polarizability must be considered. In field desorption/surface ionization experiments, alkali ion adducts with saturated alkanes have been observed [29], showing that such species can be stable, even when there is no dipole moment, if the size and structure of the molecule result in a substantial overall polarizability. Obviously, much work remains to quantitate this aspect of the experiment.

Finally, we note that for the compounds studied to date, it is intriguing that FAB provides a source of gas-phase molecules with molecular weights above $1000 \mathrm{Da}$. This capability may eventually find applications in fields other than mass spectrometry. For example $\mathrm{FAB}$ may prove to be a useful tool for the spectroscopic characterization of large molecules in the gas phase in the absence of solvent.

\section{Acknowledgments}

This work was supported by the Biotechnolugy Research Program of the Division of Research Resources of the NIH (RR00480-20), the Michigan State University Research Excellence Fund, and the Dow Chemical Company Analytical Sciences Group. We are grateful to Drs. Karen Light-Wahl, Dan Kassel, and Gary Schultz for their contributions to this project.

\section{References}

1. Barber, M.; Bordoli, R. S.; Sedgwick, D.; Tyler, A. N. J. Chem. Soc. Chem. Commun. 1981, 325.

2. Fenselau, C.; Cotter, R. J. Chem. Rev. 1987, 87, 501.

3. Cooks, R. G.; Busch, K. L. Int. I. Mass Spectrom. Ion Phys. 1983, 53, 111.

4. Sunner, J. A.; Kulatunga, R.; Kebarle, P. Anal. Chent. 1986, 58, 1312.

5. Mallis, L. M.; Russell, D. H. Int. I. Mass Spectrom. Ion Processes 1987, 78, 147

6. Bombick, D. D.; Allison, J. Anal. Chem. 1987, 59, 458.
7. Allison, J.; Ridge, D. P. J. Am. Chem. Soc. 1979, 101, 4998.

8. Rouse, J. C.; Light, K. J.; Allison, J. Proceedings of the 38th ASMS Conference on Mass Spectrometry and Allied Topics; Tucson, AZ, June 1990; p. 455.

9. Pachuta, S. J.; Cooks, R. G. Chem. Reo. 1987, 87, 647.

10. Sunner, J.; Morales, A.; Kebarle, P. Anal. Chem. 1987, 59, 1378.

11. Schröder, E.; Münster, H.; Budzikiewicz, H. Org. Mass Spectrom. 1986, 21, 707.

12. Freas, R. B.; Ross, M. M.; Campana, J. E. J. Am. Chem. Soc. 1985, 107, 6195.

13. Münster, H.; Theobald, F.; Budzikiewicz, H.; Schröder, E. Int. J. Mass Spectrom. Ion Processes 1987, 79, 73.

14. Miller, J. M.; Balasanunugam, K,; Fulcher, A. Org. Mass Spectrom. 1989, 24, 497.

15. Michaud, D. P.; Kyranos, J. N.; Brennan, T. F.; Vouros, P. Anal. Chem. 1990, 62, 1069.

16. Dahl, D. A.; Delmore, J. E. SIMION PC/PS2 Version 4.0 , EGG-CS-7233 Revision 2, April 1988.

17. MuGilvery, D.; Morrison, R. MasSIMION Version 2.0, Otober 1991.

18. Blewett, J. P.; Jones, E. J. Phys. Rev. 1936, 50, 464.

19. Ackermann, B.; Allison, J.; Musselman, B.; Pinkston, D.; Bombick, D.; Dolnikowski, G.; Tsarbopoulos, A.; Watson, J. T. Proceedings of the 31st ASMS Conference on Mass Spectrometry and Allied Topics; Boston, MA, May 1983; p. 600.

20. Kassel, D. B. Ph.D. dissertation, Michigan State University, 1988.

21. Dahl, D. A.; Delmore, J. E; Appelhans, A. D. Rev. Sci. Instrum. 1990, 61, 607.

22. Bombick, D. D. Ph.D. dissertation, Michigan State University, 1986.

23. Honda, F.; Lancaster, G. M.; Fukuda, Y.; Rabalais, J. W. I. Chem. Phys. 1978, 69, 4931.

24. Davidson, W. R.; Kebarle, P. I. Am. Chem. Soc. 1976, 98, 6133.

25. Light, K. J.; Kassel, D. B.; Allison, J. Biomed. Entiron. Mass Spectrom. 1989, 18, 177.

26. Light, K. J.; Allison, J. J. Am. Soc. Mass Spectrom. 1990, 1, 455.

27. Teesch, L. M.; Orlando, R. C.; Adams, J. J. Am. Chem. Soc. 1991, 713, 3668.

28. Weddle, G. H.; Allison, J.; Ridge, D. P. J. Am. Chem. Soc. $1977,99,105$.

29. Borchers, F.; Giessmann, U.; Röllgen, F. W. Org. Mass Spectrom. 1977, 12, 539. 